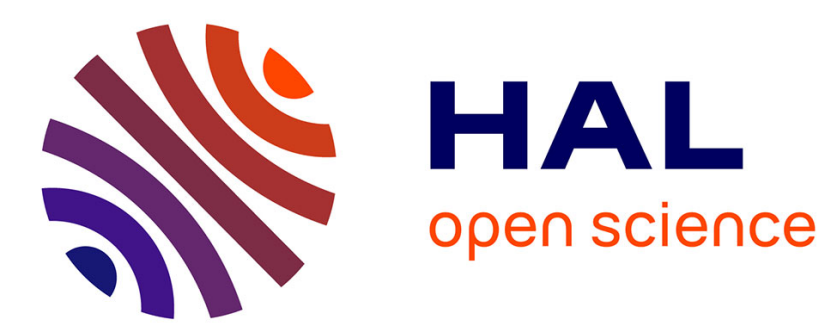

\title{
Characterization of High Purity bcc Metals by Mechanical Spectroscopy
}

\author{
M. Weller
}

\section{To cite this version:}

M. Weller. Characterization of High Purity bcc Metals by Mechanical Spectroscopy. Journal de Physique IV Proceedings, 1995, 05 (C7), pp.C7-199-C7-204. 10.1051/.jp4:1995721 . jpa-00254014

\section{HAL Id: jpa-00254014 https://hal.science/jpa-00254014}

Submitted on 1 Jan 1995

HAL is a multi-disciplinary open access archive for the deposit and dissemination of scientific research documents, whether they are published or not. The documents may come from teaching and research institutions in France or abroad, or from public or private research centers.
L'archive ouverte pluridisciplinaire HAL, est destinée au dépôt et à la diffusion de documents scientifiques de niveau recherche, publiés ou non, émanant des établissements d'enseignement et de recherche français ou étrangers, des laboratoires publics ou privés. 


\title{
Characterization of High Purity bec Metals by Mechanical Spectroscopy
}

\author{
M. Weller
}

Max-Planck-Institut für Metallforschung, Institut für Werkstoffwissenschaft, Seestrasse 92, 70174 Stuttgart, Germany

\begin{abstract}
The mechanical loss (internal friction) spectra of bcc metals (Fe, $\mathrm{Nb}, \mathrm{Ta}$ ) indicate the presence of interstitial foreign atoms by Snoek peaks at distinct, characteristic temperatures. The magnitude of the peaks is proportional to the contents of interstitial solute atoms. Experiments with single crystals allow determination of the dipole tensor components $\left|\lambda_{1}-\lambda_{2}\right|$. Equipment for low frequency measurements $\left(10^{-4} \mathrm{~Hz}-20 \mathrm{~Hz}\right)$ is demonstrated.
\end{abstract}

\section{INTRODUCTION}

Mechanical spectroscopy is based on the measurement of mechanical loss, or internal friction, as a function of temperature or frequency. Due to its selective and non-destructive nature, mechanical spectroscopy is well suited for the study of atomic defects in high purity metals. The presence of specific defects is indicated by loss maxima at distinct temperatures (or frequencies). In bec metals, such as $\alpha-\mathrm{Fe}, \mathrm{V}, \mathrm{Nb}$, or Ta, the most prominent loss maxima are due to the Snoek effect which is based on the stress-induced reorientation of foreign interstitial atoms. The loss angle, represented by $\mathrm{Q}^{-1}$ (reciprocal quality factor), can be determined either from the decay (damping) of mechanical oscillations or from the phase shift between applied stress and strain. In the mechanical loss spectra each interstitial species in a bcc metal gives rise to a Snoek peak at a distinct, characteristic temperature or measuring frequency [1, 2].

The stress induced reorientation jumps of the interstitial atoms, which cause the Snoek peaks, represent anisotropic elastic dipoles. Mechanical loss due to dipole reorientation, which is equivalent to dielectric loss of electric dipoles, can be described by the Debye equation

$$
\mathrm{Q}^{-1}(\omega \tau)=\Delta \frac{\omega \tau}{1+(\omega \tau)^{2}}
$$

Equation (1) describes a loss maximum centered at $\omega \tau=1$ with height $\mathrm{Q}_{m}{ }^{-1}=\Delta / 2$, where $\Delta$ is the relaxation strength, $\omega=2 \pi \mathrm{f}$, and $\mathrm{f}$ is the measuring frequency.

The reorientation of the interstitial atoms (dipoles) is the elementary step of interstitial diffusion. An Arrhenius equation should apply for the inverse relaxation time $\tau^{-1}$

$$
\tau^{-1}=\tau_{\infty}^{-1} \exp (-\mathrm{H} / \mathrm{kT})
$$

where $H$ is the activation enthalpy, $\mathrm{k}$ is Boltzmann's constant, and $\tau_{\infty}{ }^{-1}$ represents an atomic attempt frequency at temperature $T=\infty$. The most convenient method of mechanical spectroscopy is to measure mechanical loss as a function of temperature at constant frequency. The temperature dependence, $\mathrm{Q}^{-1}(\mathrm{~T})$, is obtained by combining equs. (1) and (2):

$$
\mathrm{Q}^{-1}(\mathrm{~T})=\mathrm{Q}_{\mathrm{m}}^{-1} \frac{\mathrm{T}_{\mathrm{m}}}{\mathrm{T}} \cosh ^{-1}\left\{\frac{\mathrm{H}}{\mathrm{k}}\left(\frac{1}{\mathrm{~T}}-\frac{1}{\mathrm{~T}_{\mathrm{m}}^{-}}\right)+\ln \left(\frac{\mathrm{f}(\mathrm{T})}{\mathrm{f}_{\mathrm{m}}}\right)\right\} \text {. }
$$

Equation (3) includes additional corrections from the weak temperature dependence of the relaxation strength $(\Delta \propto 1 / T)$ and the temperature variation of the elastic modulus (shear or Young's modulus) which is proportional to $f^{2}(T)$. Equation (3) describes a Snoek peak at $T=T_{m}$ for one interstitial species. The presence of several species leads to a superposition of several maxima, i.e. a mechanical spectrum of Snoek peaks.

Another experimental method involves measurement of the mechanical loss angle by forced vibrations at constant temperature with variation of the measuring frequency, $Q^{-1}(\omega)$. Such equipment has been recently developed [6]. 


\section{EXPERIMENTAL METHODS}

A large variety of experimental equipment have been designed for mechanical spectroscopy of materials [1,4]. One of the most versatile apparatus which is used at MPI [5] is the torsion pendulum. The basic principles are shown in Fig. 1, where the vacuum chamber and furnace are omitted for sake of simplicity. The sample is usually a thin wire or narrow strip of 0.5 to $1.2 \mathrm{~mm}$ diameter (thickness) and 40-100 mm length. It is suspended between grips and attached to a rigid base at the lower end and a movable inertia member at the upper end (i.e. an inverted pendulum). The inertia is counterbalanced so that only a small tensile static stress $(\approx 0.1 \mathrm{~N})$ is acting upward. The torsional vibrations of the sample are excited by two pairs of Helmholtz coils acting on a permanent magnet fixed to the inertia member. The oscillations are detected optically using a stabilized halogen lamp and an optical sensor (Schottky diode). Mechanical loss (internal friction) is determined from the logarithmic decrement $\vartheta$ of the freely decaying vibration amplitudes (Fig. 1b) according to

$$
\mathrm{Q}^{-1} \equiv \tan \phi=\frac{\vartheta}{\pi}(1-\vartheta / 2 \pi)
$$

$(\phi=$ loss angle). The term in paranthesis comprises a correction since the amplitude decay is not simply harmonic [1]. In the torsion pendulum mechanical loss is measured as a function of temperature, $\mathrm{O}^{-1}(\mathrm{~T})$, covering a frequency range of about 0.5 to $20 \mathrm{~Hz}$ which is dictated by the inertia member.

A new type of low frequency apparatus has been recently developed, which is based on a variable frequency at constant temperature. In principle, this subresonance apparatus is derived from the device shown in Fig. 1 by removing of the inertia member. This apparatus operates below the resonance frequency in forced vibrations. Due to the mechanical problems and the difficulty of determining small phase angles, the first low frequency subresonance apparatus was only recently developed for measurement of low damping spectra in metals [6].

The mechanical part of the new apparatus which has recently been constructed at MPI is shown in detail in Fig. 2. A sample is mounted in the same manner as in the pendulum (Fig. 1) and is suspended via a vertical rod. The suspension wire is wound and stretched around two vertically arranged pulleys. This arrangement suppresses lateral deflections of the vertical rod and it compensates, by means of the counterbalance, small vertical movement arising from thermal expansion of the specimen. Thus the low frequency torsion apparatus presented in Fig. 2 can be used for two types of loss angle measurements: (i) $\mathrm{Q}^{-1}$ as a function of frequency at constant temperature, and (ii) $\mathrm{Q}^{-1}$ as a function of temperature at constant frequency. The loss angle is determined as the phase shift between the applied alternating stress $(\sigma)$ and the resulting strain $(\epsilon)$; as indicated in Fig. $2 \mathrm{~b}$. The applied stress results from the torque produced by the permanent magnet positioned in a pair of Helmholtz coils. The excitation current $(0 \ldots 2 \mathrm{~A})$ is supplied by a galvanostsat which is controlled by an AC generator voltage from an impedance analyser (Schlumberger 1260). The resulting strain $(\epsilon)$ is detected optically (similar to in Fig. 1). The loss angle $\phi$ is determined (Fig. 1b) from the phase shift between the voltages $\mathrm{V}_{1} \propto \sigma$ and $\mathrm{V}_{2} \propto \epsilon$. The apparatus shown in Fig. 2 allows measurements of $\mathrm{Q}^{-1}=\tan \phi$ in the range of about $10^{-4} \mathrm{~Hz}$ up to $20 \mathrm{~Hz}$ with a resolution of $\Delta \mathrm{Q}^{-1} \approx 10^{-4}$. In comparison the torsion pendulum (Fig. 1), operating in free decay, allows a precision of $\Delta \mathrm{Q}^{-\mathrm{i}} \approx 10^{-6}$. The principle advantage of the low frequency subresonance apparatus is that it allows determination of $\mathrm{Q}^{-1}$ values up to 0.1 and higher, which are a factor of 10 greater than can be obtained from a torsion pendulum.

The specimen chamber shown in Fig. 2a was especially constructed for high temperature measurements up to $1400 \mathrm{~K}$. In this case the flange $\mathrm{F}$ is cooled with water. The alumina outer tube is heated by a removable $\mathrm{Pt} / \mathrm{Rh}$-furnace and it can be replaced by other specimen chambers (positioned below flange $\mathrm{F}$ ) for operation at lower temperatures.

A third type of apparatus used at MPI is based on the resonant bar technique. Specimens with the same dimensions as in the torsion pendulum are excited to flexure eigenvibrations in the $\mathrm{kHz}$ range. A detailed description is given elsewhere [7].

A demonstration of the results for $\mathrm{Nb}$ from the two experimental set-ups described above is presented in Figures 3 and 4 . Figure 3 shows a $Q^{-1}$ versus $T$ spectrum which was obtained with the torsion pendulum on a commercial $\mathrm{Nb}$ wire. According to chemical analysis [8] this specimen contained about 0.3 at $\% \mathrm{O}$ and about 0.02 at. $\% \mathrm{~N}$. The mechanical spectrum exhibits two well separated Snoek peaks, that for oxygen at $\approx 430 \mathrm{~K}$ and that for nitrogen at $\approx 565 \mathrm{~K}$. This demonstrates the selective nature of mechanical spectroscopy. Fig. 4 shows $\mathrm{Q}^{-1}$ vs. f measurements from the low frequency subresonance apparatus for three temperatures. The ultrapure $\mathrm{Nb}$ specimen was doped with 0.85 at\% $\mathrm{O}$ and its $\mathrm{O}$ Snoek maximum is shifted with increasing temperature to higher frequencies. This frequency "dispersive" apparatus permits tracking of just one Snoek maximum at an appropriately chosen temperature - contrary to the "temperature dispersive" spectra (Fig. 3). 


\section{EXPERIMENTAL INVESTIGATIONS OF SNOEK RELAXATION IN BCC METALS}

The application of mechanical spectroscopy for the characterization of bcc metals with respect to interstitial foreign atoms is mainly based on two experimental quantities:

(i) The position of the peak in terms of temperature and frequency characterizes the interstitial solute atom species. (ii) The relaxation strength $\Delta$, i.e. the magnitude of the Snoek peak, is proportional to the contents of interstitial solute atoms.

\subsection{Peak Position and Activation Enthalpy}

The temperature position of a peak (for a given frequency), $\mathrm{T}_{\mathrm{m}}$, is closely correlated with the activation enthalpy $\mathrm{H}$ for interstitial diffusion. This may be expressed by the Arrhenius equation (2) with $\omega \tau=1$ as

$$
\mathrm{H}=-\mathrm{T}_{\mathrm{m}} \mathrm{k} \ln \left(2 \pi \mathrm{f}_{\mathrm{m}} \tau_{\infty}\right)
$$

The activation enthalpy is usually determined from variation of $T_{m}$ with measuring frequency $f_{m}$. Table 1 gives a list of values for $\mathrm{H}, \tau_{\infty}$ and peak temperatures $\mathrm{T}_{\mathrm{m}}(1 \mathrm{~Hz})$ for several Snoek peaks in bcc metals $[2,3,9]$. The activation enthalpies for the Snoek peaks of $\mathrm{O}, \mathrm{N}$, and $\mathrm{C}$ in various bcc metals are plotted in Fig. 5 as a function of the peak temperature for $\mathrm{f}_{\mathrm{m}}=1 \mathrm{~Hz}$. The data can be represented by the linear relation [2]

$$
\mathrm{T}_{\mathbf{m}}[\mathrm{K}]=362 \cdot \mathrm{H} \quad[\mathrm{eV}] \text {. }
$$

This indicates that the attempt frequency $\tau_{\infty}{ }^{-1}$ is essentially a constant for Snoek peaks in bcc metals and from Fig. 5 it follows that $\tau_{\infty}^{-1}=4.8_{1} \cdot 10^{-14} \mathrm{~s}^{-1}$. Such a linear relationship of eq. (6) was first demonstrated by Wert and Marx [10].

Table 1: Snoek relaxation parameters for several combinations of bcc metal and interstitial.

$$
\mathrm{H}, \mathrm{eV}
$$

$$
\tau_{\infty}^{-1}
$$

$\underset{(\mathrm{f}=1 \mathrm{~Hz})}{\mathrm{T}_{\mathrm{m}}, \mathrm{K}}$ ref.

$\left|\lambda_{1}-\lambda_{2}\right|$

\begin{tabular}{llllll}
\hline $\mathrm{Nb}-\mathrm{O}$ & $1.15_{4} \pm 0.01$ & $3.7_{7} \pm 0.8$ & 422 & {$[2]$} & $0.61 \pm 0.01$ \\
$\mathrm{Nb}-\mathrm{N}$ & $1.57_{5} \pm 0.02$ & $8.2_{0} \pm 0.8$ & 562 & {$[2]$} & 0.65 \\
$\mathrm{Ta}-\mathrm{O}$ & $1.10_{5} \pm 0.01$ & $1.1_{7} \pm 2.5$ & 420 & {$[2]$} & $0.67 \pm 0.02$ \\
$\mathrm{Ta}-\mathrm{N}$ & $1.66_{5} \pm 0.02$ & $2.7_{5} \pm 2$ & 615 & {$[2]$} & 0.70 \\
$\mathrm{Fe}-\mathrm{N}$ & $0.82 \pm 0.01$ & $4.2 \pm 2$ & 300 & {$[18]$} & $1.0,0.97[12], 0.80[13]$ \\
$\mathrm{Fe}-\mathrm{C}$ & $0.87 \pm 0.01$ & $5.3 \pm 2$ & 314 & {$[18,19]$} & $0.83,1.06[12], 0.87[13]$
\end{tabular}

\subsection{Concentration Dependence and Relaxation Strength}

According to the simple theory the Snoek relaxation [1] strength should be proportional to the concentration $c_{o}$ of the interstitial solute atoms and this has been verified for polycrystalline specimens by numerous experiments [1,11]. For a cubic single crystal the theory gives the following equation for the relaxation strength (torsional oscillations).

$$
\Delta=\frac{4}{3} \frac{\mathrm{c}_{0} \mathrm{v}_{q}}{\mathrm{kT} \mathrm{G}}\left(\lambda_{1}-\lambda_{2}\right)^{2} \Gamma \text {. }
$$

Here $v_{0}$ is the molecular volume of the bcc metal and $\left(\lambda_{1}-\lambda_{2}\right)$ is the difference of main values of the dipole tensor with tetragonal symmetry. This dipole strength represents the ellipticity of the distortion pattern created by the interstitial atom. $\Gamma$ is the orientation parameter of the longitudinal torsional axis of the crystal, $\Gamma=\cos ^{2} \alpha \cos ^{2} \beta+\cos ^{2} \beta \cos ^{2} \gamma+\cos ^{2} \gamma \cos ^{2} \alpha(\alpha, \beta, \gamma=$ angles between longitudinal axis and cube axes) and varies between $\Gamma=0$ for a [100] direction and $\Gamma=1 / 3$ for a [111] direction. $\mathrm{G}^{-1}$ is the (elastic) compliance of the shear modulus $G$ which depends on crystal orientation, i.e. $G^{-1}=G^{-1}(\Gamma)$. Only a few experimental studies of the Snoek relaxation exist for single crystals: $\mathrm{Fe}-\mathrm{C}$ and $\mathrm{Fe}-\mathrm{N}[12,13]$ and $\mathrm{Nb}$ containing both $\mathrm{O}$ and $\mathrm{N}$ [14]. These experiments nicely demonstrated the anisotropy of the Snoek relaxation and the tetragonal defect symmetry of the interstitial atoms.

If the concentration of interstitial atoms is independently known, the shape factor $\left(\lambda_{1}-\lambda_{2}\right)$ can be determined from measurements on single crystals. Since it enters as a quadratic in eq. (7), only $\delta \lambda=$ $\left|\lambda_{1}-\lambda_{2}\right|$ is obtained. Experimental results for Nb and Ta single crystals are presented in Figs. 6 and 
7, where the specimens were prepared from ultrapure metals of $\mathrm{Nb}$ and $\mathrm{Ta}$ with $\mathrm{O}$ or $\mathrm{N}$ doping, being carried out in pure $\mathrm{O}_{2}$ or $\mathrm{N}_{2}$ after careful decarburizing and degasing (for details of specimen preparation see $[8,15]$. To avoid torsion-flexure coupling [2], single crystals with torsion axis of high symmetry ([110]) were used. Fig. 6 shows $\mathrm{Q}^{-1}$ vs. T behaviour for a $\mathrm{Nb}$ single crystal doped with 500 at.ppm $O$ along with the $\mathrm{f}^{2}$ vs. $\mathrm{T}$ plot which represents the temperature dependence of the shear modulus G. Fig. 7 depicts measurements for a $\mathrm{Ta}-184$ at.ppm $\mathrm{N}$ crystal. The interstitial concentrations were determined in each case by chemical analysis and electrical resistivity measurements. The peak height $\mathrm{Q}_{\mathrm{m}}{ }^{-1}$ in each case was determined by non-linear fitting procedure based on equation (3) [16] and the $\left|\lambda_{1}-\lambda_{2}\right|$ values are included in Table 1 . The results for $\mathrm{Nb}-\mathrm{O}$ represent an average from 3 crystals with different $\mathrm{O}$-concentrations while $\left|\lambda_{1}-\lambda_{2}\right|$ for $\mathrm{Ta}-\mathrm{O}$ was determined from two crystals. The values for $\mathrm{Fe}-\mathrm{C}$ and $\mathrm{Fe}-\mathrm{N}$ crystals are from literature and recent experiments [17].

\subsection{Applications}

Applications of the Snoek relaxation can be divided into two main categories which make use of (A) the peak position or $(B)$ the relaxation strength.

(A). The peak position indicates interstitial solute atom species present in interstitial solution. Measurement of the peak at different frequencies allow a determination of the interstitial diffusion coefficients as a function of temperature. The equipment used in our laboratory can cover a frequency range of about 6 decades $\left(10^{-3} \mathrm{~Hz}\right.$ to $\left.10^{3} \mathrm{~Hz}\right)$ with the same specimen. Comparison with high temperature diffusion experiments permits study of deviations from Arrhenius behaviour and the underlying diffusion mechanisms $[17,18]$.

(B) The utility of the relaxation strength is based on the proportional relationship between peak height and concentration of interstitial atoms in solution. Thus Snoek peak measurements have found numerous application in solubility and precipitation studies [1, 11]. Other applications are based on the interaction of interstitial atoms with other types of defects which affect the Snoek peak height. One example is the reaction of defects (vacancies, interstitial atoms etc.) produced by high energy particles irradiation with $\mathrm{C}$ or $\mathrm{N}$ in $\alpha-\mathrm{Fe}$ [20]. Another application is the study of strain aging (solute segregation to dislocations) which is indicated by a decrease of the Snoek maximum.

Finally an example of mechanical spectroscopy applied to an extraterrestrial solid is shown in Fig. 8. The specimen was cut from an iron-nickel meteorite (Gibeon, Namibia) which consists of about 92\% ferritic kamacite. The $\mathrm{Q}^{-1}$ vs. T spectrum of the untreated (as fallen) specimen showed a background without any indication of a Snoek peak. After annealing at $950 \mathrm{~K}$ a superimposed C-Snoek peak appeared at $335 \mathrm{~K}$. Its height of $Q^{-1} \approx 5 \cdot 10^{-5}$ corresponds to about 5 at.ppm $C$ in solution; this indicates that in the "as fallen" state the carbon content in solid solution is below 1 at.ppm. From the characteristic Widmannstätten structure of this meteorite it can be concluded that cooling in space occured with an extremely slow rate of about $50 \mathrm{~K}$ per $10^{6}$ years [21] which apparently leads to the complete precipitation of carbon in perfect equilibrium.

\section{Acknowledgements}

The author thanks Mr. B. Rahn and the group of A. Jaissle for technical assistance in equipment development, and to P. Keppler and R. Henes for preparation of specimens. Valuable comments of Dr. D. Whittenberger to the manuscript are gratefully acknowledged.

\section{References}

[1] Nowick A.S. and Berry B.S., Anelastic Relaxation in Crystalline Solids (Academic Press, New York and London, 1972).

[2] Weller M., J. Phys (Paris) 46, C10 (1985) 7-14.

[3] Weller M., Li G.Y., Zhang J.X., Kê T.S. and Diehl J., Acta Metall. 29 (1981) 1047-1054.

[4] Beshers D.N., "Internal Friction" Techniques of Metals Research, Vol. VII, Part 2 (Editor R.F. Bunshah, John Wiley \& Sons, New York etc., 1975), pp. 529-.707.

[5] Weller M. and Wert C., Stuttgarter Beiträge zur Naturkunde, C,18, Bernstein-Neuigkeiten, Staatliches Museum für Naturkunde, Stuttgart, 1984, pp. 85-100.

[6] Woirgard J., Sarrazin, Y., Chaumet H., Rev. Sci Instr. 48 (1977) 1322-1325.

[7] Weller M. and Török E., J. Phys. (Paris) 48, C8 (1987) 371-376.

[8] Schulze K., Grallath E. and Weller M., Zeitschriff f. Metallkde. 72, (1981) 439-444.

[9] Seeger A., Weller M., Diehl J., Pan Z.L., Zhang J.X., Kê T.S., Zeitschrift f. Metallkde. 73 (1982) 1-20. 
[10] Wert C. and Marx J., Acta Met. 1 (1953) 113-115.

[11] Fast J.D., Gases in Metals, (The Macmillan Press Ltd., London and Basingstoke, 1976).

[12] Dijkstra L.J., Philips Res. Rep. 2 (1947) 357-381.

[13] Swartz J.C., Shilling J.W. and Schwoeble A.J., Acta Met. 16 (1968) 1359-1364.

[14] Gibala R., Wert C.A., Diffusion in BCC Metals, ASM, 1965, pp. 131-148.

[15] Fromm E., Gebhardt E., Gase und Kohlenstoff in Metallen (Springer Verlag, Berlin, Heidelberg, New York, 1976).

[16] Haneczok G. and Weller, M., J. Less Comm. Metals 159 (1990) 269-276.

[17] Weller M., to be published.

[18] Weller M., Proc. "High Nitrogen Steels", Varna, Bulgaria, October 1989, 40 and 194 (1991).

[19] Haneczok G., Weller M. and Diehl J., Mat. Sci.Forum 119-121 (1993) 101-106.

[20] Weller M. and Diehl J., Scripta Metall. 10 (1976) 101-105.

[21] Goldstein J.I., Meteorite Research (P.M. Millman ed., D. Reidel, Publ. Co., Dordrecht, 1969) pp. $721-737$.

a)

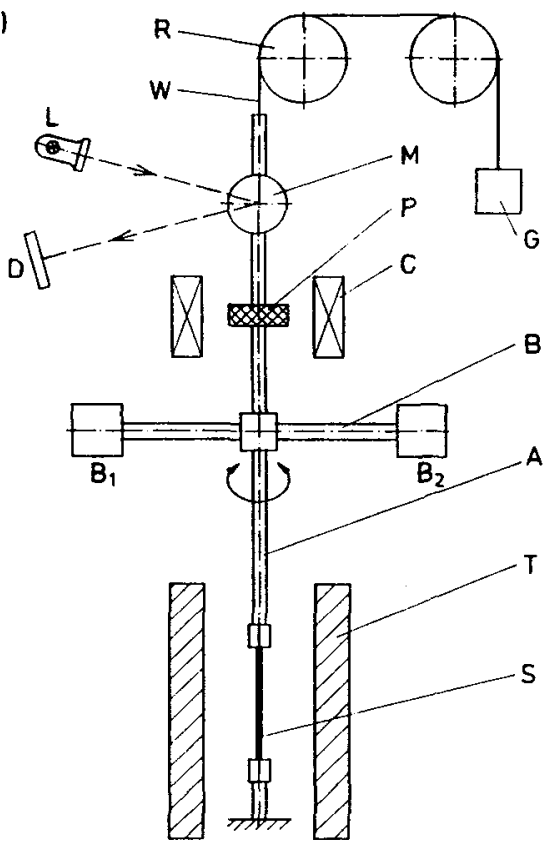

b)

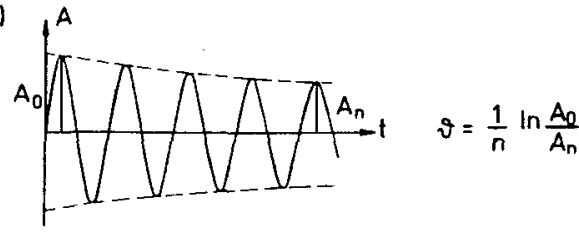

Figure 1: Schematic of (a) "Inverted torsion pendulum". S, sample; $A, B$ vertical and horizontal rods (with weights $\mathrm{B}_{1}, \mathrm{~B}_{2}$ ); G, counterweight; $M$, mirror; L, light source; $D$, optical detector; $P$, permanent magnet; $\mathrm{C}$, excitation coils; $\mathrm{T}$, cooling and heating unit; $W$, suspension wire; $R$, pulley.

b) Determination of $Q^{-1}$ from the freely decaying amplitudes. a)

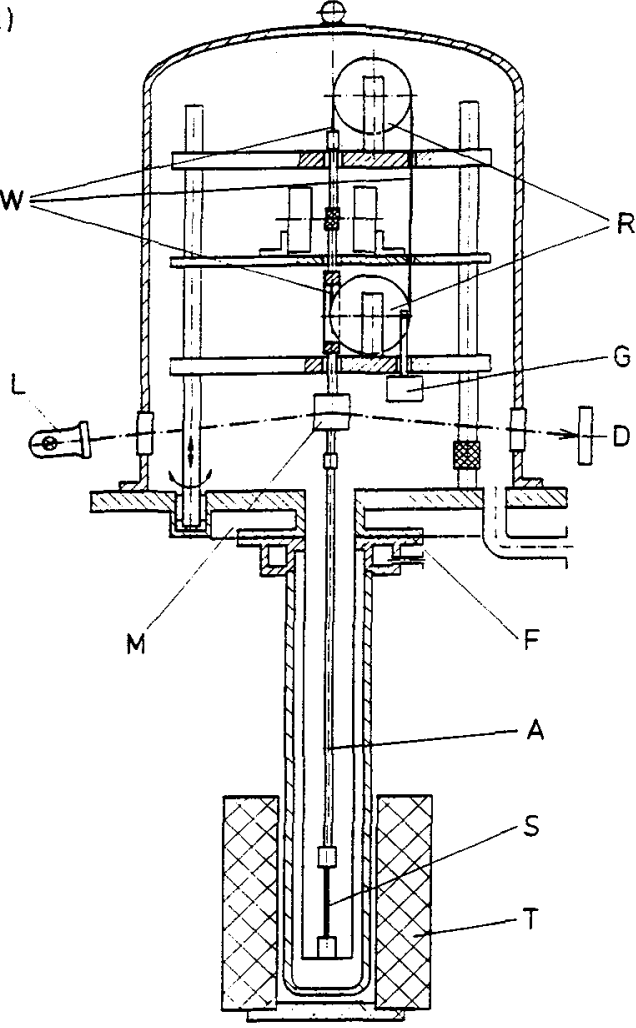

b)

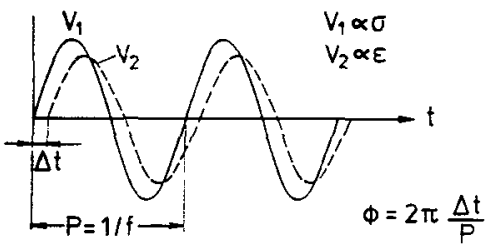

Figure 2: Schematic of "Low frequency torsion apparatus". a) Mechanical device; legend as in Fig. 1; F, flange. b) Determination of loss angle from phaseshift between stress and strain amplitude. 


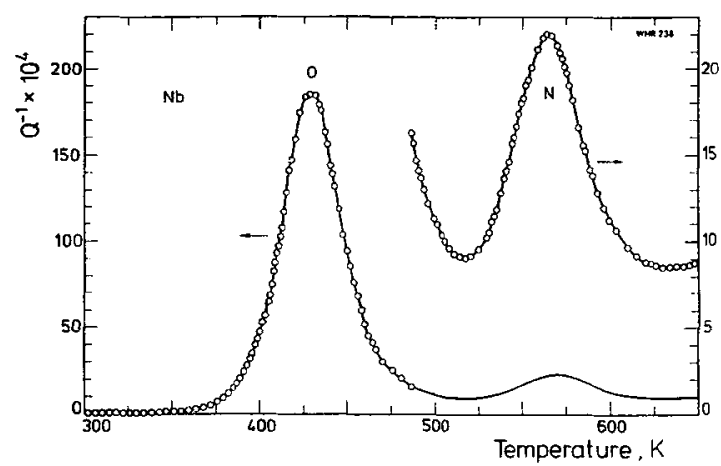

Figure 3: $\mathrm{Q}^{-1}$ as a function of temperature for a $\mathrm{Nb}$ wire with $\approx 0.3$ at. $\% \mathrm{O}$ and $\approx 0.02$ at $\% \mathrm{~N} ; \mathrm{f} \approx 1.4 \mathrm{~Hz}$. [8].

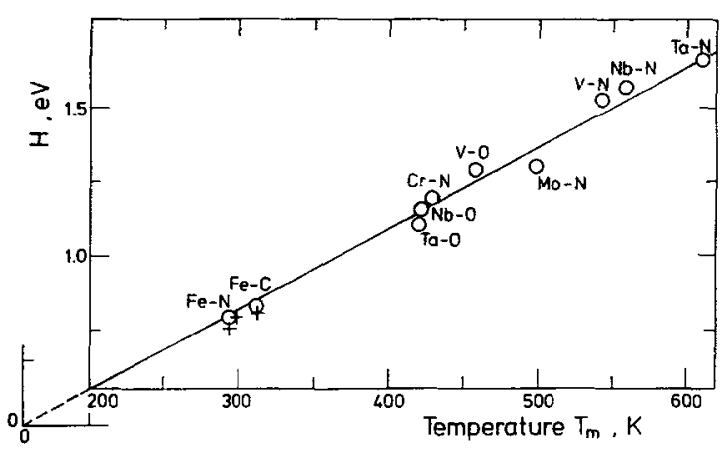

Figure 5: Activation enthalpy as a function of temperature for $O, N$, and $C$ in various bcc metals at $f=1 \mathrm{~Hz}$.

Figure 6: $\mathrm{Q}^{-1}$ and $\mathrm{f}^{2}$ as a function of temperature for a [110] $\mathrm{Nb}$ single crystal doped with 500 at.ppm $O$.

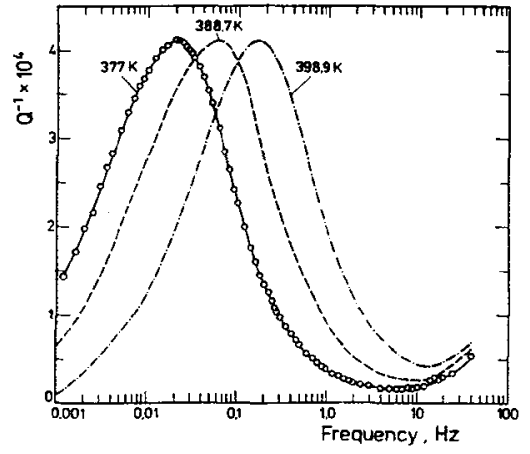

Figure 4: $Q^{-1}$ as functions of frequency and temperature for $\mathrm{Nb}$ with 0.85 at $\% \mathrm{O}$.

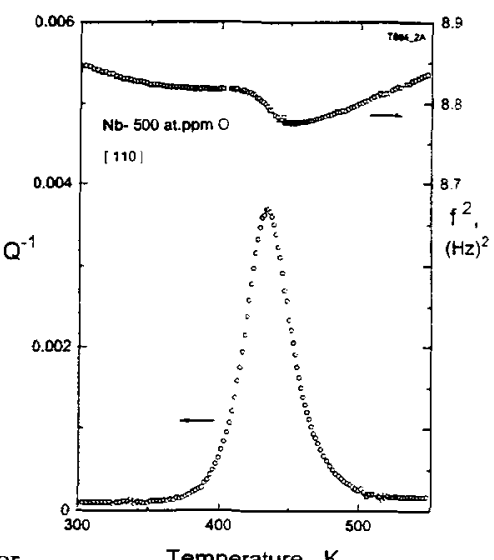

Temperature, $K$

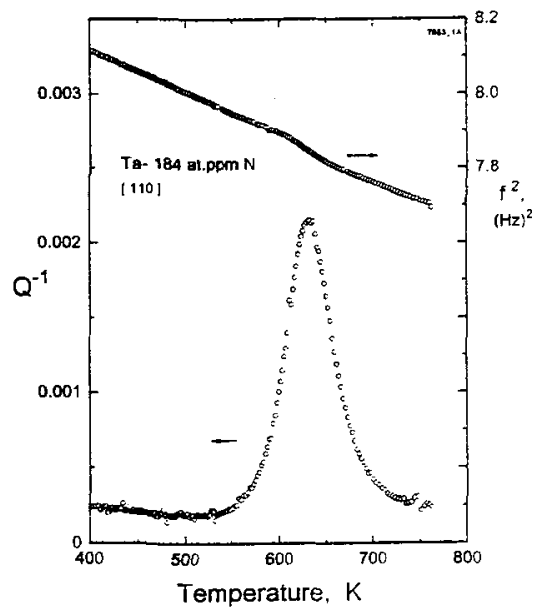

Figure 7: Same caption as Fig. 6 for a [110] Ta single crystal doped with 184 at.ppm N.

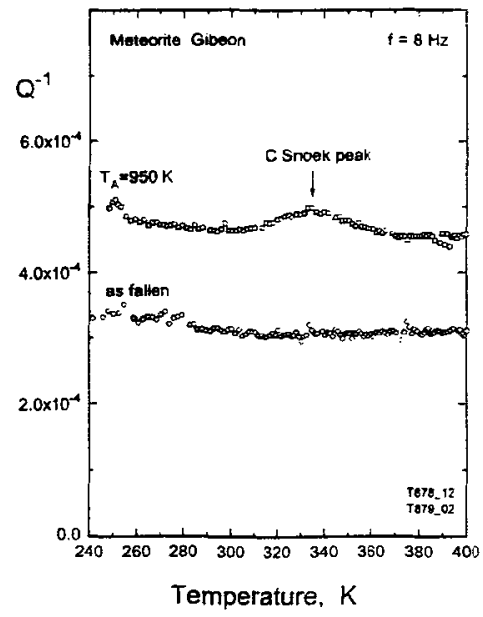

Figure 8: $Q^{-1}$ as a function of temperature for an IronNickel meteorite (Gibeon, Namibia) in the "as fallen" state and after a $950 \mathrm{~K}(200 \mathrm{~s})$ heat treatment. 